\title{
TAWAKAL DALAM PERSPEKTIF ISLAM
}

\author{
Oleh: \\ Achmad $^{1}$ \\ Email: rosulahmad9@gmail.com
}

\begin{abstract}
Man was created by God as a perfect being because he was blessed with reason so that he can distinguish between good and bad, haq and inner. There are two things that cannot be released in human life, namely endeavor and trust. Efforts are to try and do, not be silent, also not fatalistic. His conviction is quite strong and stable, while trust is an attitude of a servant who is the result of his unanimous belief in God, because he believes that only God created everything, his knowledge is extensive, he is the one who governs and controls the universe. It is this belief that drives him to surrender all his problems to God. His heart is calm and peaceful and there is no suspicion, because Allah is Omniscient and Wise, and there are still many versions of scholars in interpreting tawakal. There are 4 things that must be known in trust, namely: the meaning of trust, the degree of trust, trust in benefits, and characteristics of trust. By knowing the four points of trust, a person can strengthen himself to put his trust in God.
\end{abstract}

Keywords: Tawakal, Ikhtiar, Islamic Perspective

\section{Pendahuluan}

Manusia diciptakan oleh Allah sebagai makhluk yang paling sempurna di muka bumi ini, dikarenakan Allah meletakkan akal pada diri mereka, yang membedakan antara manusia dengan binatang adalah akal. Dalam ilmu mantiq, manusia diistilahkan dengan hayawan a-nnatiq yaitu hewan yang bisa bicara dan punya akal, sedangkan selain manusia diistilahkan hayanun ghairu a-nnatiq yaitu hewan yang tidak bisa bicara dan tidak punya akal. Dengan akal, manusia bisa memilih yang baik dan buruk, yang haq dan bathil, yang halal dan haram.

Akal berfungsi sebagai pengendali kehidupan manusia, apabila akal difungsikan secara maksimal dan baik, maka akan menuju langkah yang lebih positif, menjadikan orang bisa mendekatkan diri kepada allah, pasrah

1 Dosen Prodi Hukum Pidana Islam STAI Syaichona Moh.Cholil Bangkalan Madura 
diri (tawakal) setelah berusaha kepada Allah, dan mengerti bahwa segala sesuatu yang telah terjadi baik yang bagus atau yang jelek adalah dari Allah (خيره وشره من الش). Namun, sebaliknya apabila akal tidak difungsikan, maka manusia akan melangkah liar seperti hewan bahkan lebih liar dan sesat.

Dalam diri manusia ada dua prinsip yang harus dilaksanakan, yaitu: ikhtiar dan tawakal. Pertama manusia harus ikhtiar, arti ikhtiar adalah berupaya dan berbuat, tidak diam, juga tidak fatalistis. Keyakinannya cukup kuat dan stabil. Sebesar dan semaksimal ikhtiar, sebesar itulah hasil. Tentu berikhtiar dalam jalan yang diridoinya, bukan jalan yang tidak dibenarkan, apalagi banyak menabrak rambu dan ketentuan. Sejatinya hasil tergantung pada ikhtiar. Jika ikhtiar sekadarnya, maka sekadar pula hasilnya. Tapi jika ikhtiar dilakukan dengan sungguh-sungguh, hasilnya akan lebih optimal. Allah menegaskan dengan firmanNya dalam Surat ArRa'du berikut.

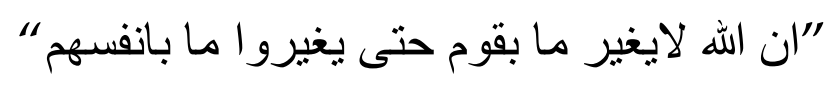

Sesungguhnya Allah tidak akan mengubah keadaan suatu kaum sebelum kaum itu sendiri mengubah apa yang ada pada diri mereka (Qs.ArRo' du, 11) $)^{2}$

Setelah prinsip yang pertama sudah dilaksanakan, maka melangkah pada prinsip yang kedua, yaitu tawakal. Tawakal yang sesungguhnya adalah tawakal yang disertai ikhtiar (usaha). Sudah menjadi sunnatullah bahwa setiap hal itu memiliki sebab dan akibat. Tidak benar jika ada orang mengaku tawakal kemudian berpangku tangan dan meninggalkan sebab atau ikhtiar. Pada hakikatnya orang seperti ini bukan orang yang bertawakal, tetapi seorang pemalas. Allah memerintahkan bertawakal, dan memerintahkan untuk mengambil sebab. Dari keterangan di atas kita tahu bahwa dua prinsip tersebut harus dipegang oleh manusia.

${ }^{2}$ Salim Bahreisy, Abdullah Bahreisy. 2001. Terjemah al-Qur'an al-Hakim. Surabaya: Sahabat Ilmu. 


\section{Pengertian Tawakal}

Secara etimologis, tawakal (توكل) atau tawakul dari kata wakala yang artinya adalah pasrah diri kepadanya ${ }^{3}$. Sedangkan tawakal secara terminologis adalah suatu sikap mental seorang hamba yang merupakan hasil dari keyakinannya yang bulat kepada Allah, karena di dalam ia diajari agar meyakini bahwa hanya Allah yang menciptakan segalanya. PengetahuanNya luas, Dia yang mengatur dan menguasai alam semesta ini. Keyakinan inilah yang mendorongnya untuk menyerahkan segala persoalannya kepada Allah. Hatinya selalu tenang dan tentram serta tidak ada rasa curiga sedikitpun, karena Allah Maha Tahu dan Bijaksana.

Sebagian ulama' (بعضهم) berkata tawakal adalah menetapkan badan untuk selalu ibadah kepada Allah, menggantungkan hati kepada Tuhan, dan tenang dengan selalu merasa cukup atas pemberian Allah. Syekh Dzun-Nun berkata tawakal adalah meninggalkan untuk mengatur diri, dan membuang jauh-jauh tipu daya dan kekuatan, dengan melihat bahwa tidak ada daya dan kekuatan kecuali milik Allah semata. ${ }^{4}$

\section{Dalil-Dalil Tentang Tawakal}

1. Dalil al-Qur'an

Dalam al-Qur'an terdapat banyak ayat yang menyinggung hal ihwal tawakal. Allah Swt menjadikan tawakal sebagai kelaziman yang tidak terpisahkan dengan keimanan. Allah berfirman:

و على الله فليتوكل المو عمنون

Dan hanya kepada Allah saja orang orang mukmin bertawakkal (QS. Ali Imran: 122)

Allah berfirman:

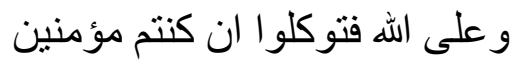

${ }^{3}$ Kamus Al-Munawwir Bhasa Arab - Indonesia

${ }^{4}$ Syekh Muhammad Amin Al-Kurdy Al-Irbily Assyafiiy Tanwirul Qulub Fi Muamalati Allamil Ghuyub (Toha Putra Semarang : t th) h.477 
Dan hanya keopada Allah hendaknya kamu bertawakkal, jika kamu benar-benar orang yang beriman. (QS. al-Maidah: 23)

Allah juga berfirman:



Sesungguhnya orang-orang yang beriman adalah mereka yang hatinya bergetar apabila disebut nama Allah, dan apabila dibacakan ayat-ayatNya kepada mereka, bertambah kuatlah imannya. Dan hanya kepada Tuhanlah mereka bertawakal. (QS. Al-Anfal: 2)

Dalam ayat yang lain, bersandar dan menyerahkan urusan hanya kepada Allah Swt, diterangkan dengan penjelasan yang lebih gamblang dan penuh penekanan. Allah berfirman:

$$
\text { رب الـ شرف والـ مغرب لاال ه الاهو ف ات خذهوك بلا }
$$

Dialah (Allah) yang menjadi Tuhan mayriq dan maghrib, tiada Tuhan yang berhak disembah selain Dia (Allah) maka ambillah dia sebagai pelindung.(QS.Al-Muzammil: 9) ${ }^{5}$

\section{Hadits}

Selain dalil dari ayat-ayat al-Qur'an yang menerangkan tawakal, dalil tentang tawakal juga banyak terdapat dalam hadits. Nabi bersabda:

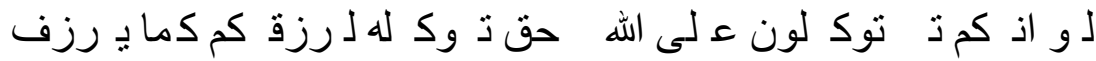

$$
\begin{aligned}
& \text { خما صا وت روح بـ طان ا(رواه الترمذي)ال ط ير ت غدوا }
\end{aligned}
$$

Andai sesungguhnya kalian tawakal pada Allah dengan tawakal yang benar, maka niscaya Allah akan memmberi rezeki kalian sebagaimana

${ }^{5}$ Salim Bahreisy, Abdullah Bahreisy. 2001. Terjemah al-Qur'an al-Hakim. Surabaya: Sahabat Ilmu 
Allah memberi rezeki kepada burung, berangkat pagi lapar dan pulang dalam keadaan kenyang (HR.Turmudzi) ${ }^{6}$

Dalam hadist yang lain dijelaskan:

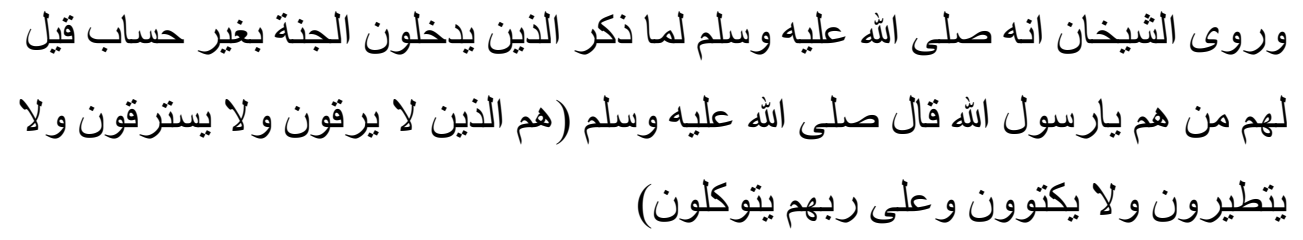

Diriwayatkan oleh dua syekh, ketika Nabi menyebutkan orang-orang yang masuk surga dengan tanpa hisab, maka diucapkan kepada beliau. Siapa mereka wahai Rasulullah. Rasulullah berkata: "Mereka adalah orang-orang yang tidak pernah ruqyah, dan pernah minta diruqyah, tidak percaya tathoyyur dan tidak melakukan pengobatan dengan "key" (berobat dengan besi panas yang ditempelkan ke tubuh), dan mereka hanya bertawakal kepada Rabb mereka" 7

Dari dalil-dalil yang telah disebut di atas, kita tahu bahwa orang yang tawakal kepada Allah akan mendapatkan segala hal yang diinginkan, dan demikian itu bisa dicapai bila disertai dengan iman yang kuat kepada Allah Swt.

\section{Derajat Tawakal}

Dalam masalah tawakal, tidak semua orang bisa bertawakal dengan model yang sama, mengingat karakter manusia yang berbeda-beda, ada yang dalam tahap pemula dan ada yang sudah sampai dalam tingkatan tawakkal yang sebenarnya. Derajat tawakal itu ada tiga, yaitu:

1. Keadaan seorang hamba hanya tergantung kepada Allah, dan percaya bahwa Allah selalu menanggung dan menolongnya seperti halnya dia percaya betul pada wakil.

${ }^{6}$ Syekh Al-Islam Muhyiddin Abi Zakariya Yahya Bin Ayarif Annawawi,Riyadus Sholihin (Toha Putra Semarang :t th) h.56

7 Syekh Muhammad Amin Al-Kurdy Al-Irbily Assyafiiy Tanwirul Qulub Fi Muamalati Allamil Ghuyub (Toha Putra Semarang : t th) h.477 
2. Keadaan seorang hamba diibaratkan seorang bayi dengan ibunya, dia hanya tergantung pada ibunya, terutama dalam hal nyusumenyusuinya, dia tidak kenal kecuali pada ibunya, dan tidak mau berpegangan kecuali kepadanya.

3. Keadaan seorang hamba dalam diam dan bergeraknya diibaratkan seperti mayat yang berada di depan orang yang memandikan, dia tidak bisa berbuat apa-apa kecuali hanya bisa pasrah. Tingkatan yang ini merupakan tingkatan yang paling tinggi dalam derajat tawakal. ${ }^{8}$

\section{Manfaat Tawakal}

Di dalam tawakal terdapat 8 manfaat yang terkandung di dalamnya, antara lain:

1. Dijamin kemudahan dunia dan akhirat

Dengan berbekal sifat tawakal maka seorang dijamin oleh Allah Swt akan selalu diberikan jalan kemudahan di dunia dan akhirat berapapun besarnya kesusahan yang dijalaninya. Allah berfirman:

"Barang siapa yang bertaqwa kepada Allah, niscaya Dia akan membukakan jalan keluar dan Dia akan memberikan rezekinya dari arah yang tidak disangka sangka.

Dan barang siapa yang bertawakal kepada Allah, niscaya Allah akan mencukupkan keperluannya. Sesungguhnya Allah melaksanakan tugasnya, sungguh dia telah mengadakan ketentuan bagi siapapun".(QS. Ath thalaq: 1-2 $)^{9}$

2. Mudah beradaptasi dengan masalah apapun.

Seseorang yang memiliki sifat tawakal, akan mudah beradaptasi dengan masalah yang seberat apapun tanpa mudah menangis dan jauh dari prasangka buruk pada Allah Swt, hanya merasa diri tidak berharga. Sifat tawakal dapat membuat seorang menjadi berhati sabar

${ }^{8}$ Al-Imam Abi Hamid Muhammad Bin Muhammad Al-Ghazali, Ihya' Ulumiddin. Darul Fikr:1994. h.278

${ }^{9}$ Salim Bahreisy, Abdullah Bahreisy.Terjemah al-Qur'an al-Hakim. Surabaya: Sahabat Ilmu. 2001. 
dan mampu bangkit kembali dari kegagalan. Dalam satu hadist dijelaskan:

“Tawakkal pada Allah adalah sumber pertolongan pada setiap kelicikan dan kejahatan dari musuhmu dan diberikan perlindungan dari apapun bentuk lawanmu"10

3. Tawakal dapat mempertebal iman dan tidak mudah putus asa.

Tawakal dapat merubah sifat egois atau mudah menyerah, menjadi lebih sabar, dan dapat pula mempertebal iman serta membuat seseorang ingin selalu berterimakasih (bersyukur) pada Allah Swt atas apa yang telah diberikan selama ini. Maka dari itu sebaik baiknya orang yang beriman adalah yang mempunyai sifat tawakal. Diriwayatkan dalam hadist bahwa:

"Semangatlah kalian pada hal hal yang bermanfaat pada kalian dan mohonlah pertolongan pada Allah. (HR.Muslim. 2664)

4. Tawakal dapat membuat seseorang menjadi lebih mandiri.

Secara tidak langsung, sifat tawakal dapat menjadikan seseorang lebih mandiri dan dewasa dalam menyelesaikan masalah dunia yang sedang dihadapinya tanpa harus merugikan pihak manapun. Sifat tawakal dapat menjadikan sesorang mampu memahami kekurangan dan kelebihan atas apa yang telah Allah berikan, kondisi ini dapat membuat sesorang menjadi lebih bisa untuk menghargai kekurangan orang lain. Allah berfirman dalam al-Qur'an:

"Hendaklah hanya kepada allah sajalah orang mukmin itu bertawakal, dan bertawakalah kepada allah yang maha hidup (abadi) yang tidak akan

${ }^{10}$ Al-Majilsi, bihar al-anwar. Vol 56 hal 79 
pernah binasa maka bertasbihlah atas dengan memujinya"(QS.Alfurqan: 58$)^{11}$

5. Allah akan mencukupkan rezeki

Allah akan mencukupkan segala kebutuhan dan kepuasan batin bagi seseorang bertawakkal semata mata karena Allah Setelah dia berusaha dan berikhtiar dengan hati yang bersih dan bersabar. Allah menjelaskan dalam firmanNya.

"Sesungguhnya allah itu mencintai dan menyayangi orang orang yang bertawakal"

Dalam satu hadist juga dijelaskan. Dari Umar bin Khattab Radiallah Anhu, dari Rasulallah Saw bersabda:

"Seandainya kalian sungguh sungguh bertawakal kepada allah, sesungguhnya akan memberi kalian rizki sebagaimana allah memberikan rizqi kepada seekor burung yang pergi dalam keadaan perutnya yang lapar lalu kembali lagi tetap dalam keadaan kenyang" (HR. Imam Ahmad, Tirmidzi, Ibnu hibban serta al-Hakim) ${ }^{12}$

6. Diberikan kenikmatan yang tiada hentinya.

Allah akan memberikan nikmatnya berupa kesenangan dalam keadaan yang tidak diduga pada semua kaum muslim yang bertawakal hanya karena Allah. Seseorang yang mau bekerja dengan jalan kebaikan, tidak pernah mengeluh dengan pekerjaannya dan selalu bertawakal selesai berikhtiar, maka akan kembali pula manfaat yang baik bagi dirinya tanpa dia duga duga sebelumnya. Ada firman Allah yang berkaitan dengan masalah kesabaran seseorang dalam menjalankan pekerjaannya yang dilakukan atas jalan kebaikan dan tawakal.

11 Salim Bahreisy, Abdullah Bahreisy. 2001. Terjemah al-Qur'an al-Hakim. Surabaya: Sahabat Ilmu

${ }^{12}$ Ibid., hlm. 56 
"Bekerjalah kamu sekalian maka allah dan rasulnya serta orang-orang mukmin akan melihat pekerjaanmu itu, dan kamu akan dikembalikan kepada allah yang maha mengetahui segala yang ghaib, dan yang nyata, lalu diberikan balasan kepadanya apa yang telah kamu kerjakan." (QS.At-taubah:105)

7. Dikuatkan hati dan dijauhkan dari godaan setan Seseorang yang bertawakal setelah berikhtiar karena Allah Swt, maka dalam hidupnya Allah akan memberikan bantuan berupa dikuatkannya hati dan dijauhkan dari godaan setan. Seperti firman Allah:

"Sungguh syetan itu tidak berpengaruh terhadap orang orang yang saleh dan beriman dan bertawakkal kepada tuhannya."(QS.an-Nahl: 99)13

8. Masuk surga tanpa proses hisab

Nabi Muhammad masuk surga tanpa proses hisab. Allah memberikan kemudahan atas segala perbuatannya yang baik dan selalu berjalan di atas kebenaran dan bertawakal dalam keadaan apapun. Sebagaimana Nabi Saw bersabda berikut.

"Mereka yang tidak membual, tidak berkata kata bohong, tidak mencuri hak orang lain, tidak membuat ramalan-ramalan yang buruk kepada rabb mereka bertawakkal, maka surga akan menjadi milikmu."

(Diriwayatkan oleh al-Buhari dan Muslim)

Nabi juga bersabda:

"Ada 70 ummatku yang akan masuk surga tanpa hisab. Mereka adalah orang orang yang tidak percaya pada masalah masalah tathayyur (kesialan), tidak meminta untuk diruqyah, dan tidak mau menjalankan pengobatan dengan key (semacam besi panas yang diletakkan pada

13 Salim Bahreisy, Abdullah Bahreisy. 2001. Terjemah al-Qur'an al-Hakim. Surabaya: Sahabat Ilmu. 
bagian tubuh seorang sebagai media pengobatan) dan bagi orang-orang yang bertawakal pada Raab mereka."14

\section{Ciri-ciri Tawakal}

Orang yang bertawakal bisa dibedakan dengan yang tidak bertawakal dengan ciri khas yang dimiliki oleh mereka, antara lain:

1. Mujahadah (semangat yang kuat)

Di antara ciri orang yang bertawakal ialah memiliki semangat yang kuat. Mempunyai semangat yang kuat merupakan akhlak orang mukmin yang dianjurkan oleh Islam. Orang mukmin yang menempuh cara semacam ini adalah orang yang lebih bagus dan lebih dicintai oleh Allah dari pada orang yang lemah semangatnya, tidak mau bekerja keras dan mengerjakan atau mencari pekerjaan yang bermanfaat.

2. Bersyukur

Ciri lain orang yang bertawakal ialah ia senantiasa bersyukur kepada Allah apabila ia berhasil dalam segala urusan ataupun ia mendapakan apa yang dibutuhkan dan diinginkan, ia tak luput untuk senantiasa bersyukur kepada Allah, karena ia menyadari dan meyakini bahwa semua yang ia dapatkan itu adalah takdir Allah dan kehendakNya. Dengan bersyukur pula ia akan selalu merasa puas, senang dan bahagia.

3. Bersabar

Ciri orang yang bertawakal selanjutnya adalah selalu bersabar. Sebagai orang mukmin yang bertawakal kepada Allah ia akan bersabar, baik dalam proses maupun dalam hasil. Karena dengan inilah ia akan bahagia dan tenang atas apa yang diterimanya. Rasulallah bersabda:

"Orang yang bahagia ialah orang dijauhkan dari fitnah-fitnah dan orang yang terkena ujian dan cobaan dia bersabar" (HR.Ahmad dan Abu Daud)

4. Intropeksi diri (muhasabah)

Orang yang bertawakal salah satu sifatnya adalah intropeksi diri. Dimana ia akan intropeksi diri apabila ia kurang sukses dalam

${ }^{14}$ Ibid.,. hlm.477 
menjalankan sesuatu, ia tidak membuat dirinya jatuh, melainkan ia selalu introspeksi pada diri, dapat dikatan muhasabah, senantiasa mengoreksi apa yang telah dilakukannya. Setelah itu ia akan berusaha menghindari faktor penyebab suatu kegagalan tersebut serta senantiasa memberikan yang terbaik pada dirinya. ${ }^{15}$

\section{Penutup}

Setiap individu harus mempunyai sikap tawakal, sebagai bentuk implementasi penyerahan diri kepada yang Kuasa. Tawakal adalah suatu sikap mental seorang hamba yang merupakan hasil dari keyakinannya yang bulat kepada Allah, karena di dalam ia diajari agar meyakini bahawa hanya Allah yang menciptakan segalanya, pengetahuannya luas, Dia yang mengatur dan menguasai alam semesta ini. Keyakinan inilah yang mendorongnya untuk menyerahkan segala persoalannya kepada Allah. Hatinya tenang dan tentram serta tidak ada rasa curiga, karena Allah Maha Tahu dan Bijaksana.

${ }^{15}$ Achmad, “Tawakal dalam Perspetif Islam” http://m.inilah.com/news. Detail.ini. dan diakses 01 Oktober 2019 


\section{DAFTAR PUSTAKA}

Al-Qur'an al-Karim 30 Juz. 1991. Semarang: Toha Putra.

Al-Ghazali, Al-Imam Abi Hamid Muhammad Bin Muhammad, 1994, Ihya' Ulumiddin Bairut: Darul Fikr

Al-Majilsi. Bihar al-Anwar. Vol 56 hal 79

Annawawi, Syekh Al-Islam Muhyiddin Abi Zakariya Yahya Bin Syarif, Riyadus Sholihin. Semarang: Toha Putra.

Assyafiiy, Syekh Muhammad Amin Al-Kurdy Al-Irbily. Tanwirul Qulub Fi Muamalati Allamil Ghuyub. Semarang: Toha Putra.

Bahreisy, Salim \& Bahreisy, Abdullah . 2001. Terjemah al Qur'an al Hakim Surabaya.

http: m.inilah.com/news. dan diakses 01 Oktober 2019 